
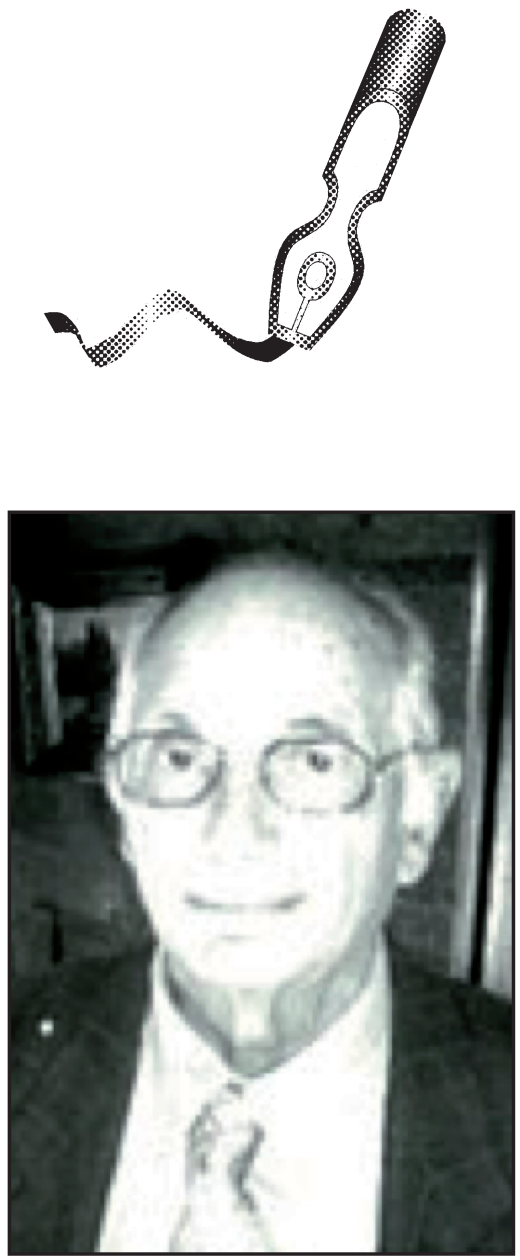

\title{
Benjamín Rosenblüt Gasman
}

Revista Otorrinolaringología y Cirugía de Cabeza y Cuello, órgano oficial de la Sociedad de Otorrinolaringología, Medicina y Cirugía de Cabeza y Cuello lamenta profundamente la partida de su ex director Dr. Benjamín Rosenblüt Gasman acontecida el 14 de septiembre del año en curso en la ciudad de Santiago. La triste noticia del fallecimiento de quien fuera nuestro Jefe, Maestro y amigo durante muchos años nos conmovió profundamente.

El Dr. Rosenblüt ingresó a la Escuela de Medicina de la Universidad de Chile y posteriormente trabajó como otorrinolaringólogo en el Hospital San Juan de Dios en donde llegó a ocupar la subjefatura. Siempre en su trayectoria profesional destacó como investigador y autor de numerosos trabajos científicos publicados en revistas nacionales y extranjeras. Entre los años 1956 y 1960 realizó el posgrado en audiología en la Washington University de Saint Louis, con posterioridad a lo cual elaboró el listado de palabras fonéticamente balanceadas para pruebas de discriminación, las que actualmente son utilizadas y llevan su nombre. Siempre demostró especial dedicación a la docencia y en conjunto con todos con los que trabajó o dirigió formaron un grupo imposible de olvidar y que atrajo por su excelencia a muchos jóvenes a su lado.

Por todos sus logros académicos obtuvo el título de Profesor Titular de Otorrinolaringología y Profesor Honorario de la Universidad de Chile e internacionalmente el de ser miembro del Collegium Oto-Rhino-Laryngologicum Amicitiae Sacrum.

En su trayectoria profesional fue distinguido permanentemente y con ocasión del $50^{\circ}$ Congreso Chileno de ORL en Viña del Mar, fue nombrado Miembro Honorario y que motivaron palabras en el discurso homenaje de la Sociedad: “...destacar a un hombre, mezcla rara de una inteligencia bien dotada, y ciertamente bien aprovechada, asociada a una hidalguía de corazón y de inclaudicables valores éticos que han marcado un sendero estrecho, en el que pocos han caminado...". Posteriormente en el Congreso de Puerto Varas recibió el galardón más significativo de nuestra Sociedad al ser nombrado Maestro de la Otorrinolaringología.

Como integrante del Comité Redactor y luego Director de nuestra revista durante 20 años consecutivos, desarrolló con especial dedicación una labor sacrificada y dif́cil pero que ha permitido que su impronta dure hasta hoy. Debió enfrentar una compleja situación en los años 70, durante el cual numerosos colaboradores médicos se 
alejaron del Comité Editorial, lo que significó momentos de penurias económicas muy serias a tal punto que la publicación de la revista pudo mantenerse inalterable gracias a su propia generosidad y que en sus propias palabras explicó “... pero lo que importa es que salimos adelante y gracias a la generosidad de muchos profesionales fuera posible que un número importante de médicos se formara en esta especialidad...".

En todas sus participaciones y conversaciones siempre recordó especialmente a sus maestros, Ios doctores Santiago Riesco McClure y Raúl Velasco y a sus queridos pares de esa época Drs. Arturo Tello, Jorge Duclos, Jorge Otte Gabler, Osvaldo Emhart, Fernando de la Fuente y Jorge Otte García.

En un período de gran producción científica en otoneurología y otología, el Dr. Rosenblüt rescató la rinología para nuestra especialidad, especialmente en campo de la septoplastía y rinoplastía. Su experiencia en USA le permitió desarrollar en nuestro país numerosos cursos de rinoplastía con discípulos del Dr. Cotle, como los Drs. Klaff y West.

En 1995 asumió la Jefatura del Servicio de Otorrinolaringología del Hospital Clínico de la Universidad de Chile. En este hospital tuvimos el privilegio de su jefatura, amistad, motivación y consejo permanente lo que me obliga ahora a escribir a título personal y quizás representando a muchos.

Benjamín según el Antiguo Testamento corresponde al hijo menor de Jacob y literalmente significa hijo del sur, interpretado en el Génesis como el hijo de la mano auspiciosa o buena y eso es lo que Benchito significó para nosotros un hombre bueno, un hombre derecho, un hombre auspicioso y un hombre querible e inolvidable. El marcó la vida de muchos y particularmente la mía. Conocí con él la capacidad de liderazgo, la tolerancia del jefe, la autoridad bien entendida, la motivación entusiasta, la comprensión, la admiración y por si lo anterior fuera poco, la amistad, llena de anécdotas e historias de vida. Para mí fue una persona muy especial con la cual muchas veces reímos y lloramos. Estimado Benchito le ofrezco a Ud. y familia, a través de su revista mis sentimientos y recuerdos más profundos.

Por último una reflexión que no es de mi autoría y ya publicada en la Revista y que ilustra lo que el Dr. Rosenblüt nos dejó.

Efectuar un trabajo científico es prender una estrella Presentarlo a otros, es la maravilla de ver una estrella fugaz Publicarlo, es dejar una estrella que puede guiar el camino de otros

Jorge Caro Letelier

\section{BENJAMÍN ROSENBLÜT GASMAN}

Nos ha dejado un personaje multifacético. Un hombre culto, conocedor del mundo, médico tratante, otorrinolaringólogo, investigador, docente, padre de familia y cultivador de la amistad.

Su cultura se manifestaba en su amena conversación donde se podía hablar de literatura, filosofía, artes plásticas y musicales y sobre todo, de la vida. 
Como médico tratante destacó por su dedicación a los pacientes sin discriminación de su condición social ni económica.

En la especialidad de otorrinolaringología destacó por sus conocimientos en audiología siendo un colaborador importante en la creación de las listas de palabras que se usan en castellano para el estudio de la discriminación auditiva. Tan importante es su colaboración en las investigaciones sobre los mecanismos de la audición y los estudios preliminares de los potenciales eléctricos auditivos que conducirían, posteriormente, al diagnóstico precoz de alteraciones profundas de la audición en los recién nacidos, lo que se ha concretado actualmente en que desde muy temprana edad puedan habilitarse, gracias los programas de nuestro Ministerio de Salud. En cirugía de la especialidad fue un adelantado en el desarrollo de la cirugía cosmética funcional nasal.

Como docente participó activamente en la formación de pregrado de los futuros médicos, pero más interesante fue su docencia de posgrado donde numerosos especialistas reconocen su impronta.

Perteneció a numerosas sociedades científicas: Sociedad Chilena de Otorrinolaringología, Sociedad Andina, que incluye la confraternidad con los colegas cuyanos, Sociedad Chilena de Otoneurología y Neuroftalmología, pero su orgullo era pertenecer al Collegium Oto-Rhino-Laryngologicum Amicitiae Sacrum (CORLAS). A este grupo sólo se podía integrar por invitación y donde se reunían los más prestigiosos investigadores y especialistas. Publicó numerosas experiencias de investigación científica en varias revistas de la especialidad.

Todos estos antecedentes hacen que sea nombrado Profesor Titular de Otorrinolaringología. Subjefe del Servicio del Hospital San Juan de Dios de donde pasa a ser Jefe del Servicio del Hospital Clínico de la Universidad de Chile, donde después de varios años jubila. Además el Comité Docente de la Sociedad Chilena de Otorrinolaringología lo honra con el título de Maestro de la Especialidad.

Después del sensible fallecimiento del doctor Santiago Riesco MacClure, fundador de la Revista Chilena de Otorrinolaringología, que posteriormente pasa además a titularse como de y Cirugía de Cabeza y Cuello deviene a ser el director de la misma. El alma de la Revista es el denominado Comité Redactor, apodado como "el combativo". Está formado por los mejores especialistas nacionales quienes pulen, corrigen y hacen que las publicaciones sean lo más cercanas a la perfección. En los años sesenta el financiamiento de la revista se vuelve complicado y, con gran esfuerzo, ingenio y voluntad él consigue que no se pierda la continuidad de la publicación.

Nuestra especialidad, por iniciativa de nuestros primeros maestros y del Comité Redactor, organizaba reuniones mensuales rotativas entre los distintos servicios para que ellos expusieran sus inquietudes y experiencias, se denominaron CEPE (Centro de Estudios para la Especialidad) tradición que aún persiste mucho más formal y organizada y al finalizar el año se seleccionaban las mejores ponencias y se realizaba con ellas un mini congreso que se denominó Jornadas Anuales que se celebraban en Valparaíso.

Por iniciativa del doctor Carlos Celedón las humildes Jornadas se transformaron en lo que hoy es el Congreso Chileno Anual de la Especialidad cuyo primer Presidente fue Benjamín. Conocido es el aporte que estos congresos dan a nuestra especialidad tanto en el avance e intercambio de conocimientos así como en el financiamiento de la investigación que realizan nuestros estudiantes de posgrado. 
También tuvo una destacada participación en los dos congresos internacionales que se efectuaron en Chile: el Congreso Latinoamericano de Otorrinolaringología en el que participó en el Comité Científico y en el Congreso Panamericano de Otorrinolaringología como Presidente. Ellos se vieron realzados por numerosos especialistas de alto nivel gracias al conocimiento personal y prestigio que tenía Benjamín.

Tuve la fortuna de conocer a Benjamín en su entorno familiar. Un gran jefe de familia con una esposa e hijos así como a sus cónyuges y nietos disfrutando de su amistad. Fue en estas instancias cuando Bencho, en ocasiones Benchito compartimos viajes, vivencias, conversaciones en las que repetía su lema: "La amistad es como una flor que hay que cultivar". En este sentido era un excelente jardinero.

No es original pero viene al caso, desapareció la persona pero nace la leyenda. Las generaciones que formaste y a las que entregaste conocimiento y amistad continúan tu obra.

Juan Viada Lozano

\section{BENJAMÍN ROSENBLÜT GASMAN}

Hablar del Profesor Benjamín Rosenblüt es hablar de un Maestro, pero más que maestro, yo diría un testigo, es decir, una persona que fue capaz de dar testimonio en su vida académica. Fue Profesor Titular de la Universidad de Chile, pero quizás ese no fue su mérito principal. No es difícil llegar a ser Profesor Titular aunque sea de la Universidad de Chile, mucho más difícil es llegar a ser Maestro que evidentemente lo fue, pero aún es más exigente ser testigo, es decir, dar testimonio de su condición académica. Tenía claro que la docencia y la investigación universitaria no es sólo una formalidad; el cumplir normas y juntar antecedentes para alcanzar cierta jerarquía académica.

El Prof. Rosenblüt tenía cualidades humanas que lo ponían por sobre su condición de Maestro y Testigo y fue lo que lo llevó a ser un líder en la formación tanto de pre como de posgrado en otorrinolaringología. Soy testigo de varios de esos liderazgos. En un momento en que estábamos un grupo de becados con muy escasa docencia, fue capaz, en un acto de humildad y consecuencia y dando testimonio de su vocación universitaria, ir a buscar al Profesor Arturo Tello, del cual se encontraba distanciado por diferentes circunstancias de la vida; para que nos viniera a hacer docencia en cirugía de cavidades perinasales. Este tipo de actitudes en que se siente el deber y la vocación universitaria frente a sus alumnos, postergándose así mismo; es lo que hace grande al Profesor, Maestro y Testigo Rosenblüt.

No vale la pena hablar de sus antecedentes académicos por todos conocidos y que evidentemente fueron muchos. Me ha parecido más relevante resaltar sus condiciones humanas de Profesor, Maestro y Testigo, porque son precisamente esas condiciones con todo lo que ello implica, lo que lo hizo líder en la formación de especialistas.

Carlos Celedón Lavín 